\title{
The Type A Phages of Salmonella typhimurium: the Significance of Mixed Clones Arising from Singly-Infected Bacteria
}

\author{
By J. S. K. BOYD AND D. E. BIDWELL \\ The Wellcome Laboratories of Tropical Medicine, The Wellcome Building, \\ Euston Road, London, N.W. 1
}

(Received 25 May 1964)

\begin{abstract}
SUMMARY
Salmonella typhimurium Q1, when grown in standard medium at a temperature of $37^{\circ}$, is a uninuclear organism in which nuclear division precedes cell division, so that some 25 to $30 \%$ of the bacteria show various stages of nuclear division. When incubated at a lower temperature (e.g. $25^{\circ}$ ) nuclear division outruns cell division, and binucleate and quadrinucleate forms appear. In experiments at $37^{\circ}$, infection of $Q 1$ or superinfection of Q1 (A 1 a) with temperate phage $A 1$ b temporarily arrests bacterial division, producing a lag period of 30-45 min. Decision to lyse is taken from 1 to $9 \mathrm{~min}$. after exposure to infection, and the ensuing productive development leading to the release of a brood of temperate phage particles is an immediate sequel of this decision. Decision to lysogenize, as evidenced by immunity to a heavy challenge by homologous virulent phage, is taken within one minute of infection. 60 to $70 \%$ of bacteria infected or superinfected with a single phage particle produce pure clones of lysogenized, prophage-substituted, or doubly lysogenized bacteria. It is suggested that the mixed clones of uninfected and converted bacteria derived from the remaining 30 to $40 \%$ may result from the lysogenization of one-half of a nucleus already embarked on the process of division; evidence favouring this theory is discussed. It is concluded that, contrary to current belief, and under the conditions of our experiments, the infective material of a phage particle which has penetrated a sensitive bacterium proceeds with little delay either to become integrated with the chromosome as prophage or to undergo productive development and produce lysis, and does not remain for one or more bacterial generations an unattached cytoplasmic inclusion.
\end{abstract}

\section{INTRODUCTION}

The events which intervene between the penetration of a sensitive bacterium by the infective material of a temperate phage particle, and the ultimate attachment of this material to the bacterial chromosome as prophage, present problems of considerable interest. Several facts suggest that this process of lysogenization may be completed without delay and certainly before the infected bacterium divides. Thus, while the decision to lyse is usually taken within the first $10 \mathrm{~min}$. both by virulent phage and by the virulent particles of temperate phage, the decision to lysogenize is made even more quickly, is immediately dominant over lysis, and confers an immunity which resists indefinitely the aggression of heavy infections of homologous virulent phage. Accompanying the development of this immunity, there is a 
well-marked prolongation of the division time of the first generation of phageinfected bacteria which is not seen in subsequent generations, and which suggests a considerable but transient disturbance of the bacterial metabolism at nuclear level. This disturbance might well be related to the integration of the phage DNA into the bacterial chromosome. However, it is currently held (references will be given in the discussion) that the phage genetic material remains as a free cytoplasmic inclusion for one or more bacterial generations before it becomes prophage; accordingly during this period each division of the bacterium which carries the inclusion produces one potentially lysogenic and one sensitive daughter cell, thus giving rise to a mixed clone of sensitive and infected organisms. We found difficulty in reconciling this conclusion with certain observations made when working with Salmonella typhimurium $\mathbf{Q} \mathbf{1}$ and the $\mathbf{A}$ phages which lysogenize it, and decided to investigate the problem in more detail.

\section{METHODS}

The materials and methods used were mainly those described in previous papers of this series (Boyd, 1950; Boyd \& Bidwell, 1957, 1959, 1961, 1962). The bacterial strains were Salmonella typhimurium $\mathrm{Q} 1$ and $S$. typhimurium $\mathrm{Q} 1$ (A 1 a). The phages, both temperate and their virulent mutants, were members of the $A$ series. Phage $A 1 \mathrm{~b}$ is believed to be identical with phage $\mathbf{P 2 2}$, since both were isolated from the same bacterial strain.

The smears subsequently stained by Giemsa's method were prepared on coverslips, dried in the incubator, fixed in absolute ethanol for 5 min., washed, hydrolysed in $\mathrm{N}-\mathrm{HCl}$ for $9 \mathrm{~min}$., very thoroughly washed in distilled water, stained overnight in dilute Giemsa stain (1 drop of Giemsa stain to $1 \mathrm{ml}$. of buffer in distilled water, $\mathrm{pH} 7 \cdot 0$ ), washed in the same buffer, dried and mounted. For convenient reference, details of certain of the methods used are given in the text.

Terminology. Clones of unchanged Salmonella typhimurium Q1 or Q1 (A1a) are designated 'uninfected'; clones showing lysogenization, prophage substitution or double lysogenization are designated 'converted'; clones containing both uninfected and converted bacteria are referred to as 'mixed'.

\section{The nuclei of Salmonella typhimurium $\mathbf{Q 1}$}

It is not infrequently stated that in the exponential state of growth rod-shaped bacteria are multinucleate, containing two or more nuclei (Bertani, 1953, 1958; Jacob \& Wollman, 1953). This is a matter of some importance in investigating the progeny of newly lysogenized cells, as is also the occurrence of 'doublets', i.e. bacteria nearing the stage of division (Bertani, 1960). In lysogenization experiments it would obviously be ideal to use cultures in which division of the bacteria had been synchronized. However, in our hands attempts to produce synchronization by the method described by Lark \& Maaløe (1954) were unsuccessful, and we had recourse to the use of cultures in which multiplication had been decreased to a minimum, though even in such preparations the percentage of bacteria in process of division was considerable. The number and developmental state of the nuclei was determined by examining the bacteria either by phase-contrast illumination or in stained smears. Samples were taken from standard cultures at the stage of preparation corresponding to zero-point in the experiments, i.e. immediately before the addition of 
infecting or superinfecting phage. For phase-contrast examinations, $1 \mathrm{ml}$. of $\mathbf{4 0 \%}$ $(\mathrm{w} / \mathrm{v})$ formaldehyde was added to $9 \mathrm{ml}$. of the culture, and a measured volume of the formalin-treated culture was added to an equal quantity of melted agar in a test tube, which was then thoroughly shaken. A small drop of this mixture was placed on a heated slide, a coverslip applied and pressed firmly down to give as thin a layer of agar as possible, and the edges of the preparation were sealed with melted Vaseline. The bacteria, being trapped in the now solidified agar, were quite motionless and easy to examine. The Giemsa-stained smears were examined with a $\frac{1}{16}$ in. oil immersion lens and a $\times 25$ ocular. With strong illumination through a compensating condenser, the purple-stained nuclear masses were clearly defined. The two methods gave very similar results. In the smallest bacteria, which were short, almost oval in

\section{Table 1. Percentage of bacteria showing nuclear division in a standard broth culture of Salmonella typhimurium}

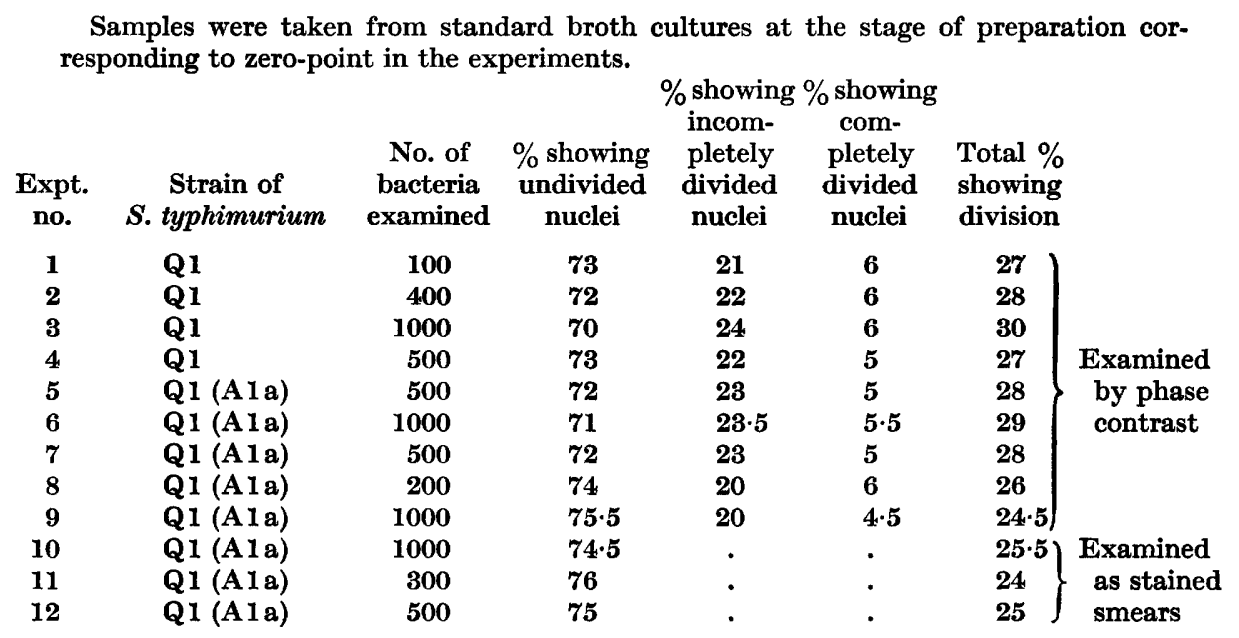

shape, and obviously the product of a recent division, there was a single small nuclear mass. At the other end of the scale there were 'doublets' (Bertani, 1960) with two distinct nuclei separated by an indentation in the bacterial wall. Between these two extremes were intermediate forms in all stages of development towards division. As the bacterium elongated, the nucleus also became more rod-shaped and ultimately showed, at the middle of its long axis, an indentation which appeared before any corresponding indentation of the cell wall was seen. As far as Salmonella typhimurium $\mathrm{Q} 1$ is concerned, therefore, the doublet conception is correct. When in the logarithmic phase of growth at $37^{\circ}$, the bacterium is uninucleate, and two separate nuclei can be seen only when its division is imminent. Counts made in a number of preparations, both by phase-contrast illumination and by the direct examination of stained smears, are recorded in Table 1.

In some experiments an attempt was made to differentiate three grades, uninucleate, binucleate (on the point of division) and intermediate forms with elongated nuclei showing a greater or lesser degree of indentation. In others only two types were recorded, those with unindented ovoid nuclei and those with elongated nuclei showing indentations of all degrees up to complete division. In the cultures used in 
these experiments, examined at the time when, in the lysogenization experiments, phage was added, approximately $5 \%$ of the bacteria had double nuclear masses, and a further $20-25 \%$ had elongated nuclei showing various degrees of indentation. None of the many thousands of bacteria examined was quadrinucleate.

Since these results were at variance with the findings of Lark, Maaløe \& Rostock (1955), we repeated the experiment following more or less the technique used by these workers. A broth culture of Salmonella typhimurium $\mathrm{Q} 1$ which had been kept at a temperature of $25^{\circ}$ for $5 \mathrm{hr}$ was raised to $37^{\circ}$ by adding broth warmed to $90^{\circ}$, and was maintained at $37^{\circ}$ in a water bath. At intervals after the temperature was raised to $37^{\circ}$, smears were prepared and stained with Giemsa. Binucleate and quadrinucleate bacteria as described by Lark et al. (1955) were seen in the early smears, but after $60 \mathrm{~min}$. at $37^{\circ}$, when active multiplication was established, the picture had reverted to normal, and the organisms in the culture had the characters we found in our preparations. It would therefore seem that, when growth takes place at a temperature of $\mathbf{2 5}^{\circ}$, nuclear division runs ahead of cellular division, producing multinucleate forms. When, however, the culture is restored to the optimum temperature for multiplication, cellular division takes place immediately after nuclear division, so that the bacteria are uninucleate except when they are about to divide.

\section{The lag period following bacteriophage infection}

Preliminary experiments showed that the smooth progress of the growth curve of a culture of Salmonella typhimurium in broth was upset by minor and transient variations of temperature and by the addition of relatively small quantities (10\%) of the culture merium in which the organism was growing. To overcome these difficulties, all culture media, phage preparations, pipettes, etc., were maintained and used at a temperature of $37^{\circ}$. Broth, inoculated with the organism under test taken from an overnight culture on nutrient agar, was incubated for $2 \mathrm{hr}$ at $37^{\circ}$. Two ml. of this culture were added to $15 \mathrm{ml}$. broth and incubated at $37^{\circ}$ for a further $45 \mathrm{~min}$., when it contained approximately $10^{8}$ organisms $/ \mathrm{ml}$. This is the preparation referred to as a 'standard' culture. Of this culture $4.95 \mathrm{ml}$. were placed in each of two test tubes. To one, the control, $0.05 \mathrm{ml}$. of broth was added: to the other $0.05 \mathrm{ml}$. of a phage suspension adjusted to give, in the final concentration, $10^{9}$ particles $/ \mathrm{ml}$. (or more or less, according to the phage : bacteria ratio required). The tubes were returned to the water bath at a temperature of $37^{\circ}$ and, except in experiments in which it was necessary to time from the moment phage was added, a period of $5 \mathrm{~min}$. was allowed for adsorption to occur. Thereafter samples were removed at predetermined intervals, diluted as required, and plated in $\mathbf{0 . 5} \mathrm{ml}$. quantities either on nutrient agar in the case of the controls, or on nutrient agar impregnated with virulent phage when counts of lysogenized bacteria were required.

Curves of the rate of multiplication of newly lysogenized bacteria in five members of the series are given in Fig. 1. The lag periods varied from 30 to $45 \mathrm{~min}$. In the case of newly lysogenized Salmonella typhimurium Q1 (A1 b), Q1 (A1 c) and Q1 (A3) the rate of multiplication, once the lag period was passed, was similar to that of the control. In the case of S. typhimurium Q1 (A2d) and particularly Q1 (A2 e), the rate of division was slower than normal.

Lag curves were also plotted (Fig. 2) in certain superinfections known to give a high rate of prophage substitution or double lysogenization (Boyd \& Bidwell, 1962). 
Superinfection of Salmonella typhimurium Q1 (A1a) with phage A1b and phage A 1c provided good examples of the progress of bacterial multiplication following prophage substitution. As might be expected, the lag period in these superinfections was similar to that found in heavy infections of $S$. typhimurium Q1 (see Fig. 1 ). Subsequent multiplication was at a slightly slower rate than in a control culture of

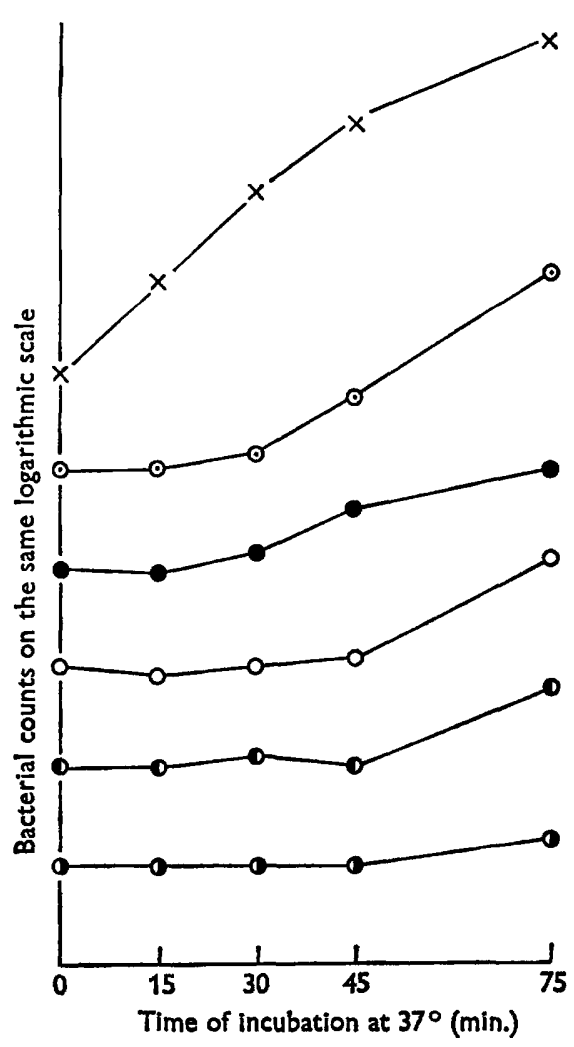

Fig. 1

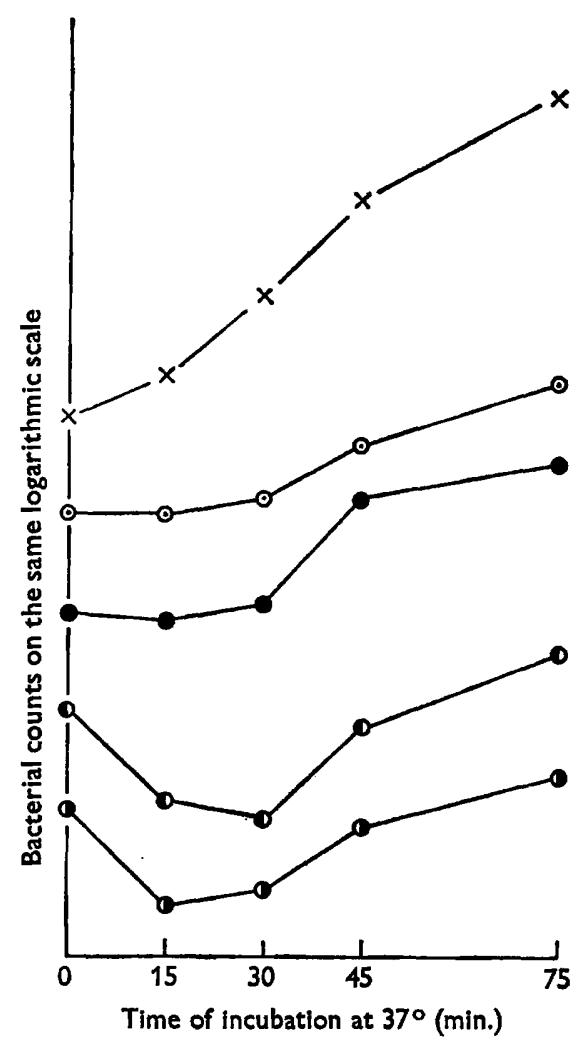

Fig. 2

Fig. 1. The lag period in simple lysogenization. The points on the curves are counts of viable bacteria made from cultures maintained at $37^{\circ}$ in a water bath. The control is uninfected Salmonella typhimurium Q1, and the remaining five curves record the lysogenic bacteria in identical cultures exposed to the various phages in a phage: bacteria ratio of 10:1. The bacterial viable counts at zero were approximately $10^{8} / \mathrm{ml}$. The subsequent counts are plotted on the same logarithmic scale as the control, and therefore show comparable slopes. $\times$, is $S$. typhimurium $Q 1$; $O, Q 1$ exposed to phage $A 1 b$; $O$, exposed to phage A1 c; $O$, exposed to phage A $3 ; 0$, exposed to phage A2d; $O$, exposed to phage A2e.

Fig. 2. The lag period in superinfection. Legend as in Fig. 1, except that the culture used was Salmonella typhimurium Q1 (A1a). In superinfection with phages A2d and A2e, note the decrease in viable bacteria during the first $30 \mathrm{~min}$. of incubation. $\times$, is $\mathrm{S}$. typhimurium Q1 (A1a); $\odot$, is $Q 1$ (A1 a) exposed to phage A1 b; $\odot$, exposed to phage A1 c; D, exposed to phage A2d; $O$, exposed to phage A2e.

S. typhimurium Q1 (A 1 a). Superinfection of S. typhimurium Q1 (A 1 a) with phages A2c, A2d and A2e (giving double lysogenization) produced an unexpected result. After incubation for $15 \mathrm{~min}$. the number of viable doubly lysogenic organisms 
decreased to about one-half the number present in the sample plated immediately after exposure. This finding was readily repeated. To confirm that this decrease in the number of lysogenized bacteria was not caused by lysis resulting from productive development, total counts (by microscope) and viable counts (by culture) of S. typhimurium Q1 (A1 a) superinfected with phage A2d, and of a control culture of S. typhimurium Q1 (A 1 a), were carried out in parallel (Table 2). The total count showed no decrease corresponding to the decrease in number of viable doublylysogenized bacteria.

\section{Table 2. Correlation of total and viable counts of Salmonella typhimurium} Q1 (A1a) and Q1 (A1a) superinfected with A2d

A standard culture of S. typhimurium Q1 (A1 a) was divided into two portions and phage A2d was added to one of them to give a phage: bacteria ratio of 10:1.

Total counts of bacteria were made by microscopical methods, and include both viable and non-viable organisms. Viable counts were made by plating measured quantities on nutrient agar, incubating overnight, and examining for its prophage content each colony which developed from the superinfected sample. The decrease by over $50 \%$ of the doubly-lysogenized organisms which took place during the first $15 \mathrm{~min}$. of incubation had no counterpart in the corresponding total count nor in the counts of the control S. typhimurium Q1 (A1a).

\begin{tabular}{|c|c|c|c|c|c|}
\hline \multirow{3}{*}{$\begin{array}{l}\text { Time of } \\
\text { incubation } \\
\text { (min.) }\end{array}$} & \multirow{2}{*}{\multicolumn{2}{|c|}{ S. typhimurium Q1 (A1a) }} & \multicolumn{3}{|c|}{ with phage A2d } \\
\hline & & & \multirow[b]{2}{*}{ Total count } & \multirow{2}{*}{$\begin{array}{l}\text { Viable count } \\
\text { Q1 (A1 a) }\end{array}$} & \multirow{2}{*}{$\begin{array}{c}\text { Viable count } \\
\text { Q1 (A1a. A2d) }\end{array}$} \\
\hline & Total count & Viable count & & & \\
\hline 0 & $1.45 \times 10^{8}$ & $8 \cdot 1 \times 10^{7}$ & $1.4 \times 10^{8}$ & $4.56 \times 10^{7}$ & $2.04 \times 10^{7}$ \\
\hline 15 & $1.72 \times 10^{8}$ & $9.26 \times 10^{7}$ & $1.45 \times 10^{8}$ & $4 \cdot 4 \times 10^{7}$ & $9.66 \times 10^{8}$ \\
\hline 30 & $1.99 \times 10^{8}$ & $1.5 \times 10^{8}$ & $1.48 \times 10^{8}$ & $5 \cdot 0 \times 10^{7}$ & $1 \cdot 1 \times 10^{7}$ \\
\hline
\end{tabular}

\section{Development, subsequent to penetration, of infecting or superinfecting phage}

Most of the reported observations on the processes of lysis and lysogenization have been made on bacteria exposed to concentrations of phage sufficiently high to give a preponderance of multiple infections. We have preferred to experiment with a low phage:bacteria ratio, giving single infections of most of the bacteria. Such a technique is laborious because of the large proportion of blanks (uninfected bacteria) in every experiment, but gives results which avoid any fallacy which may result from multiple infection. Earlier work (Boyd \& Bidwell, 1961) showed that when a culture of Salmonella typhimurium Q1 was exposed to a concentration of temperate phage sufficiently low to give single infections, some of the bacteria were lysogenized and others were lysed after productive development of the phage. Under standard conditions all the type A phages produce relatively constant proportions of lysogenesis and lysis, but each member of the series has its own lysogenesis:lysis ratio. We explain this phenomenon by postulating: that the particle which becomes prophage is adequately endowed with some property essential for establishing lysogenesis; that the temperate particle which produces lysis is deficient but not wholly lacking in this property; that the virulent mutant, which by the use of a suitable technique can be recovered from most temperate phage suspensions (Boyd, 1951) and which is incapable of producing lysogenesis, is completely devoid of it. These concepts are recapitulated here because they have an important bearing on the interpretation of the experiments which follow. 
Decision to lyse; virulent phage. Lwoff, Kaplan \& Ritz (1954) found that when Salmonella typhimurium 1404 (an indicator strain used in earlier experiments) was exposed simultaneously to high concentrations of a temperate Ala phage and a virulent mutant of this same phage (temperate phage ratio 11:1, virulent phage ratio $9: 1$ ) the temperate phage proved to be dominant, and produced the same percentage of surviving (lysogenized) bacteria as a control in which the bacteria were exposed only to the temperate phage. These workers also did lysogenization experiments : $(a)$ in media to which 5 -methyltryptophan had been added, $(b)$ with incubation at a temperature of $42^{\circ}$, and $(c)$ in medium containing citrate which was subsequently neutralized by the addition of magnesium sulphate. The results were claimed to show that the critical time at which the decision to lyse or lysogenize was reached lay between the 6 th and 9 th minute after infection, and that at this time the genetic material of the phage became irrevocably committed to one or other of these lines of development.

\section{Table 3. Domination of temperate phage over virulent phage}

Standard preparations were used. The \% of Salmonella typhimurium survivors was ascertained by plating suitably diluted quantities on nutrient agar. All survivors in (2) were found to be lysogenic.

Time of incubation (min.)

\begin{tabular}{|c|c|c|c|c|}
\hline 0 & 3 & 6 & $\mathbf{9}$ & 12 \\
\hline \multicolumn{5}{|c|}{$\begin{array}{c}\% \text { of surviving } S . \text { typhimurium organisms in samples } \\
\text { taken after incubation for times indicated }\end{array}$} \\
\hline $56 \cdot 2$ & $4 \cdot 8$ & $\mathbf{0 . 3 3}$ & 0.7 & 0 \\
\hline $75 \cdot 2$ & $38 \cdot 8$ & 8.6 & 0.73 & o \\
\hline
\end{tabular}

(2) Same as (1), but with temperate phage $A 1 \mathrm{~b}$ added in a 10:1 ratio at the time of sampling, and allowed to act for $10 \mathrm{~min}$. before plating

We have repeated the first of the experiments of Lwoff et al. with Salmonella typhimurium $\mathbf{Q} 1$ and phage $A 1$ b (Table 3 ); the culture of $S$. typhimurium $Q 1$ was infected with a 10:1 ratio of the virulent mutant of phage $A 1 \mathrm{~b}$, and to this mixture temperate phage $A 1 \mathrm{~b}$ was added at intervals to give a 10:1 ratio. As in the experiment of Lwoff et al., the protective power of the temperate phage was well marked when it was added shortly after the bacteria had been exposed to the virulent phage, but this protective power was absent when the temperate phage was added 9 min. after this exposure. However, it is noteworthy that, in terms of the time-interval, the decline in the protective power of the temperate phage was graded, and that, after as short an interval as $3 \mathrm{~min}$., approximately only one-half of the bacteria which were protected at zero time were 'saved' by the temperate phage.

Decision to lyse; temperate phage. Salmonella typhimurium Q1 was exposed to a concentration of temperate phage A 1 b calculated to give $15-20 \%$ of lytic reactions (Boyd \& Bidwell, 1961), and an excess of the same temperate phage was added to portions of this infected culture at 3-min. intervals (Table 4). The time interval until the decision to lyse became irreversible was rather longer than in the case of sensitive 
bacteria exposed to virulent phage. In some of the bacteria the point of no return was reached in $6 \mathrm{~min}$.: after $12 \mathrm{~min}$. the addition of excess temperate phage did not produce any protective action.

Table 4. Time of decision to lyse (i.e. undergo productive development). Temperate phage $A 1 b$ and Salmonella typhimurium $Q 1$

Temperate phage A1 b to give a low phage:bacteria ratio was added to a standard culture of $S$. typhimurium $Q 1$ and the resulting mixture distributed into a number of test tubes which were then incubated at $37^{\circ}$. Excess of temperate phage $\mathrm{Al} \mathrm{b}$ to give a high phage: bacteria ratio was added to successive tubes at $8 \mathrm{~min}$. intervals. The $\%$ of 'bursts' was estimated by the method described in a previous communication (Boyd \& Bidwell, 1961).

Mixture of temperate phage $\mathrm{A} 1 \mathrm{~b}$ and $S$. typhimurium $\mathrm{Q} 1$ to give a phage : bacteria ratio of $0.5: 1$

\begin{tabular}{|c|c|c|c|c|}
\hline \multirow{2}{*}{$\begin{array}{l}\text { No further } \\
\text { temperate } \\
\text { A1 b added }\end{array}$} & \multicolumn{4}{|c|}{$\begin{array}{l}\text { Temperate phage } A 1 \mathrm{~b} \text { to give a phage: bacteria ratio of } \\
10: 1 \text { added after incubation for time ( } \min .) \text { indicated }\end{array}$} \\
\hline & $\mathbf{3}$ & 6 & 9 & 12 \\
\hline \multicolumn{5}{|c|}{$\%$ of 'bursts' } \\
\hline 14 & 0 & $2 \cdot 1$ & 7 & $18 \cdot 4$ \\
\hline
\end{tabular}

\section{Table 5. Time of decision to lysogenize; temperate phage $A 1 \mathrm{~b}$ and Salmonella typhimurium $Q 1$}

Temperate phage A1 b was added to $50 \mathrm{ml}$. of a standard culture of $S$. typhimurium Q1 to give a phage: bacteria ratio of $0.5: 1$, and the mixture distributed in $0.5 \mathrm{ml}$. quantities into a series of tubes and incubated at $87^{\circ}$. From one series of tubes samples were taken at 3 min. intervals and the \% of lysogenized bacteria determined by plating $0.5 \mathrm{ml}$. of $10^{-5}$ dilution on a lawn of Salmonella typhimurium $\mathbf{T}$ gal- on galactose agar (Boyd \& Bidwell, 1961), this technique being adopted in preference to the 'impregnated agar' method to avoid exposing the bacteria to excess of virulent phage $A 1 \mathrm{~b}$. To a second series virulent phage $A 1 \mathrm{~b}$ to give a 10: 1 ratio was added at corresponding intervals, and after incubation for a further $5 \mathrm{~min}$. the \% of bacteria lysogenized was determined by plating $0.5 \mathrm{ml}$. of $10^{-5}$ dilutions on nutrient agar and counting the lysogenic colonies which developed.

\begin{tabular}{|c|c|c|c|}
\hline \multirow[b]{3}{*}{$\begin{array}{l}\text { Time of } \\
\text { sampling } \\
\text { (min.) }\end{array}$} & \multicolumn{3}{|c|}{$\begin{array}{c}\text { Temperate phage A1 b added to } S \text {. typhimurium } \\
\text { Q1 in a 0.5:1 ratio }\end{array}$} \\
\hline & \multicolumn{2}{|c|}{$\%$ of bacteria lysogenized } & \multirow[b]{2}{*}{$\begin{array}{l}\text { Time of adding } \\
\text { virulent } \mathbf{A} 1 \mathbf{b} \\
\text { (min.) }\end{array}$} \\
\hline & In control & $\begin{array}{l}\text { Virulent phage } \\
\text { A1 b added to } \\
\text { give a 10:1 ratio }\end{array}$ & \\
\hline 1 & 3 & $5 \cdot 6$ & 1 \\
\hline 4 & $10 \cdot 6$ & 14.8 & 4 \\
\hline 7 & $17 \cdot 6$ & $19 \cdot 6$ & 7 \\
\hline 10 & $15 \cdot 5$ & $16 \cdot 3$ & 10 \\
\hline 13 & 12 & $16 \cdot 3$ & 13 \\
\hline
\end{tabular}

Decision to lysogenize; temperate phage. A standard culture of Salmonella typhimurium $Q 1$ was infected with a low concentration of phage $A 1 \mathrm{~b}$, giving a phage: bacterium ratio of $0.5: 1$, and then divided into two portions. From the first portion (the control) samples were removed at intervals and the percentage of lysogenized bacteria therein calculated. At the same intervals virulent phage A1 b was added to 
measured volumes from the second portion to give a 10:1 ratio. After incubation for 5 min. to allow the virulent phage to be adsorbed, the percentage of lysogenized bacteria in this test series was also calculated. The results (Table 5) show that the percentage of lysogenic responses was slightly greater in the test series than in the control, a variation which can be attributed to differences in the techniques followed. The apparent delay in lysogenization seen in both control and test can be accounted for by the low phage concentration and the interval of time which consequently elapsed before all the phage particles came in contact with bacteria, since a standard culture of $S$.typhimurium $Q 1$ exposed to a high concentration of temperate phage $\mathrm{A} 1 \mathrm{~b}$ produced maximum lysogenization much more quickly (Table 6). The salient fact which emerges from the experiment recorded in Table 5 is that the temperate phage had established its decision to lysogenize in the earliest stages of the test, and maintained this decision in the face of a heavy challenge by virulent phage.

\section{Table 6. Establishment of immunity}

Temperate phage A 1 b was added to Salmonella typhimurium Q1 in a $10: 1$ ratio.
Samples were taken at the times recorded, diluted to $10^{-4}$ in antiphage serum to neutralize
free phage, and plated on agar impregnated with virulent phage A1 b. The percentages
of bacteria lysogenized (immune to virulent phage) were calculated in terms of a control
culture not exposed to either temperate or virulent phage.
Time of sampling (min.):
\% of bacteria lysogenized
\%

Onset of productive development. Productive development is an immediate sequel to the decision to lyse. This is readily seen when the phage: bacteria ratio is low, say 1:10 (Fig. 3). Adsorption led to a decrease in the count of free phage particles for about $15 \mathrm{~min}$. (More detailed experiments, not recorded here, showed that adsorption was in fact overtaken by phage production in 18-20 min.) Thereafter phage production continued actively for the next $45 \mathrm{~min}$., reaching in about $40 \mathrm{~min}$. a concentration sufficient to produce, quite abruptly, lysogenization in the majority of the bacteria which had escaped infection at the beginning of the experiment. There was no detectable clearing of the culture until about the 80th min., and little change in the total count of viable bacteria in $120 \mathrm{~min}$.

Establishment of lysogenesis. In doing experiments to determine the immediate fate of the infective material of a lysogenizing temperate phage which has just penetrated a sensitive bacterium, it was deemed advisable to eliminate certain possible sources of error. The first precaution is one which we believe to be of great importance. Only stable 'wild' phages were used: they were from lines which have never been subjected to artificial mutagenic influences, and which, over the many years they have been in use, have never produced any mutants other than the virulent type previously described (Boyd, 1951) which can be recovered without difficulty from all the temperate A phages except phage A4. No semi-virulent forms have ever been encountered, nor when culturing together different members of the group have we, with one possible exception, found any evidence of genetic recombination, although this possibility was constantly in mind. Secondly, we have confined our observations to experiments with low multiplicities calculated to produce a majority of single infections, and we have not used more than one type of infecting phage in any one experiment. 
Two slightly different techniques were used to obtain clones from single organisms. In one a standard culture of Salmonella typhimurium Q1 (or Q1 (A 1 a) for superinfections) containing about $10^{8} \mathrm{bacteria} / \mathrm{ml}$. was infected with phage $\mathbf{A} 1 \mathrm{~b}$ at a 0.5:1 ratio. After $5 \mathrm{~min}$., or in some experiments $10 \mathrm{~min}$., at $37^{\circ}$ to allow adsorption to take place, the culture was diluted $10^{-7} \times 1 / 16$ in broth, and a $0.4 \mathrm{ml}$. sample of this dilution placed in each of 100 to 150 small sterile tubes, giving a distribution of one bacterium per four tubes. After further incubation for a standard time (as

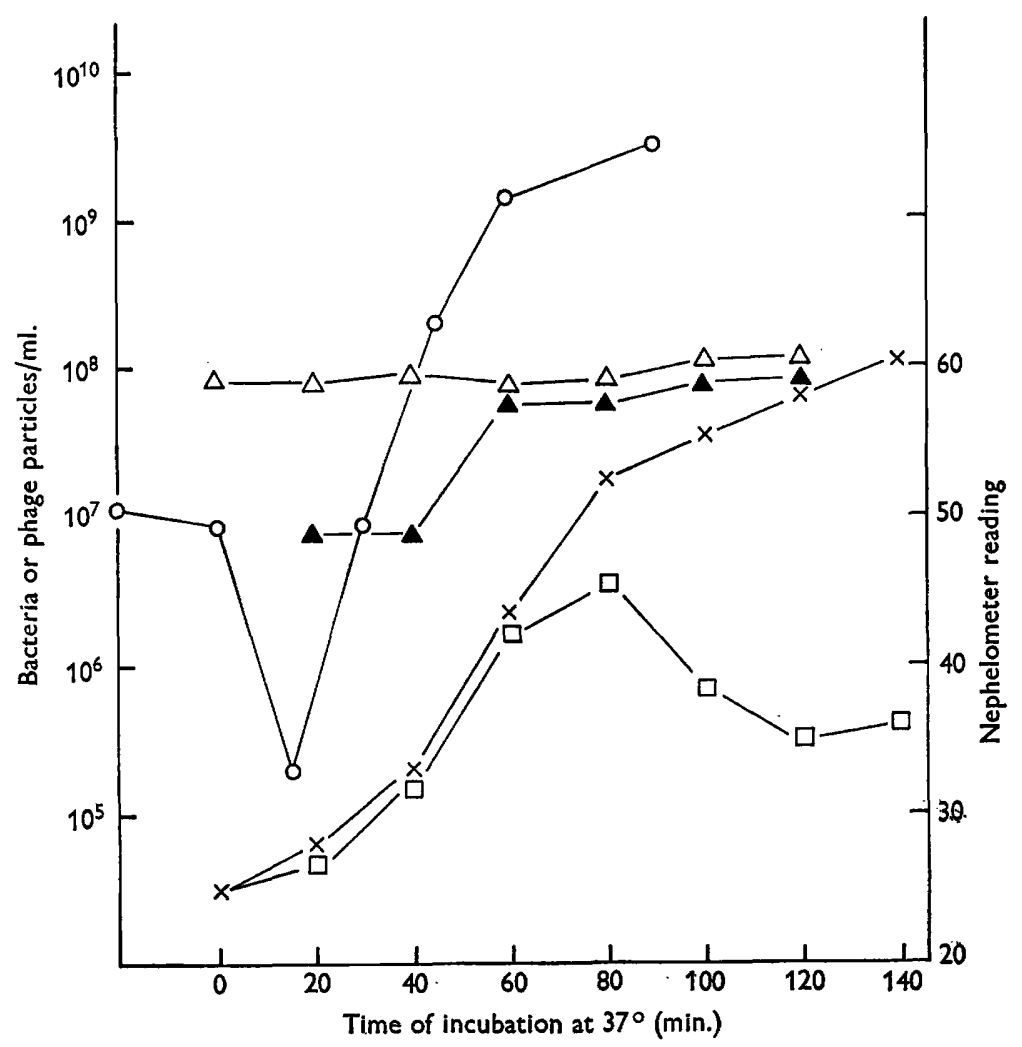

Fig. 3. Onset of lysis, primary and secondary lysogenization, and clearing of the culture. A standard culture of Salmonella typhimurium Q1 was exposed to phage $A 1 \mathbf{b}$ in the low phage: bacteria ratio of $1: 10$. Lysis, revealed by the production of free phage, began around $15 \mathrm{~min}$. Primary lysogenization was at its peak by $20 \mathrm{~min}$. Secondary lysogenization of residual sensitive bacteria took place between 40 and $60 \mathrm{~min}$., when there was a high concentration of free phage. Clearing of the culture did not occur until around $80 \mathrm{~min}$. $O$, free phage; $\triangle$, count of all viable bacteria, lysogenized and non-lysogenized; $\Delta$, count of lysogenic bacteria; $\times$, turbidity curve of control; $\square$, turbidity curve of infected culture.

detailed later) the contents of each tube were flooded over a plate of nutrient agar and incubated overnight. Colonies developed on about $25 \%$ of the plates, and each colony on every plate was examined for lysogenicity. Where the second technique was followed, the infected culture was distributed, not into small tubes, but into $5 \mathrm{ml}$. screw-cap bottles. After the standard period of incubation, each bottle was half filled with melted nutrient agar at $45^{\circ}$ and culture and agar thoroughly mixed. 
The bottles were then placed in the hot-room $\left(37^{\circ}\right)$ and left there overnight. Colonies which developed in the depth of the medium were easily reached with a platinum needle and were subjected to the usual examination for lysogenicity. The diadvantage of this second method was that, in a variable number of bottles in each batch, one or more of the bacteria found its way into the water of condensation and

Table 7. The average number of Salmonella typhimurium bacteria arising from the division of a single organism after standard incubation

Temperate phage $\mathrm{A} 1 \mathrm{~b}$ was added to standard cultures of $S$. typhimurium $\mathrm{Q} 1$ and Q1 (A 1 a) in a ratio of 0.5:1 and, after incubation for $10 \mathrm{~min}$. at $37^{\circ}$, diluted and distributed in tubes or $5 \mathrm{ml}$. screw-cap bottles in quantities calculated to give not more than 1 organism per tube or bottle. After further incubation sufficient to allow two or three bacterial divisions to occur $(a)$ the contents of each tube were poured over a plate of nutrient agar, or (b) a quantity of nutrient agar was added to each bottle and thoroughly mixed with the culture. Each colony which developed after incubation was examined for lysogenicity. The figures are compiled from the results of 27 experiments.

S. typhimurium Q1 exposed to phage A1 b

\begin{tabular}{|c|c|c|c|c|c|c|c|}
\hline $\begin{array}{c}\text { Type of } \\
\text { colony }\end{array}$ & $\begin{array}{l}\text { No. of } \\
\text { tubes or } \\
\text { bottles }\end{array}$ & $\begin{array}{l}\text { No. of } \\
\text { colonies }\end{array}$ & Average & $\begin{array}{l}\text { Type of } \\
\text { colony }\end{array}$ & $\begin{array}{l}\text { No. of } \\
\text { tubes or } \\
\text { bottles }\end{array}$ & $\begin{array}{l}\text { No. of } \\
\text { colonies }\end{array}$ & Average \\
\hline $\begin{array}{l}\text { Q1 (un- } \\
\text { changed) }\end{array}$ & 110 & 511 & $4 \cdot 6$ & $\begin{array}{l}\text { Q1 (A1 a) } \\
\text { unchanged }\end{array}$ & 107 & 487 & $4 \cdot 55$ \\
\hline Q1 (A 1 b) & 30 & 89 & 3 & Q1 (A1 b) & 20 & 58 & $\mathbf{2 \cdot 9}$ \\
\hline $\begin{array}{l}\text { Mixed } \\
\text { Q1 } \\
\text { Q1 (A I b) }\end{array}$ & 20 & $\begin{array}{l}41 \\
57\end{array}$ & $\begin{array}{l}2 \cdot 05 \\
2 \cdot 85\end{array}$ & $\begin{array}{l}\text { Mixed } \\
\text { Q1 (A 1 a) } \\
\text { Q1 (A 1 b) }\end{array}$ & 17 & $\begin{array}{l}59 \\
48\end{array}$ & $\begin{array}{l}3 \cdot 5 \\
2 \cdot 8\end{array}$ \\
\hline
\end{tabular}

Table 8. Progeny of single organisms of Salmonella typhimurium Q1 exposed to a low concentration of phage $A 1 b$

For technique see Table 7.

\begin{tabular}{|c|c|c|c|c|c|c|}
\hline & & & \multicolumn{4}{|c|}{ Converted } \\
\hline & \multicolumn{2}{|c|}{ Uninfected clones } & \multicolumn{2}{|c|}{ Pure clones Q1 (A1 b) } & \multicolumn{2}{|c|}{$\begin{array}{c}\text { Mixed clones Q1 and } \\
\text { Q1 (A1 b) }\end{array}$} \\
\hline Expt. no. & Total & $\begin{array}{l}\text { Clones of } 10 \\
\text { or more } \\
\text { organisms }\end{array}$ & Total & $\begin{array}{l}\text { Clones of } 10 \\
\text { or more } \\
\text { organisms }\end{array}$ & Total & $\begin{array}{c}\text { Clones of } 10 \\
\text { or more } \\
\text { organisms }\end{array}$ \\
\hline 1 & 15 & 1 & 5 & - & 一 & - \\
\hline 2 & 22 & 1 & 7 & - & 3 & 1 \\
\hline $\mathbf{3}$ & 14 & $\mathbf{1}$ & 2 & - & $\mathbf{3}$ & - \\
\hline 4 & 6 & $\mathbf{1}$ & 4 & - & 3 & 1 \\
\hline $\mathbf{5}$ & 9 & $\mathbf{2}$ & 2 & — & 2 & - \\
\hline 6 & 15 & - & 1 & - & - & - \\
\hline 7 & 8 & $\longrightarrow$ & 2 & - & $\longrightarrow$ & - \\
\hline 8 & 11 & 1 & 2 & - & $\mathbf{I}$ & - \\
\hline $\mathbf{9}$ & 2 & - & 3 & 一 & 1 & - \\
\hline 10 & 8 & - & $\mathbf{3}$ & - & 5 & - \\
\hline 11 & 5 & - & 3 & - & 1 & - \\
\hline 12 & 10 & - & 3 & - & $\mathbf{1}$ & - \\
\hline 18 & 11 & - & 5 & - & - & - \\
\hline 14 & 12 & - & 6 & - & 2 & - \\
\hline Grand total & 148 & 7 & 48 & $\ldots$ & 22 & 2 \\
\hline
\end{tabular}


in multiplying overgrew the surface of the medium; bottles thus affected were discarded. The advantage of this method was economy of medium, and the certainty that all viable bacteria were examined, since none was lost by transfer from one container to another.

To ascertain the optimum time of incubation needed for adequate but not excessive multiplication of the bacteria, calculations were made from the lag-curve experiments already described. They showed that, in these experiments which began at a

Table 9. Progeny of single organisms of Salmonella typhimurium Q1 (A1a) exposed to a low concentration of phage $A 1 b$

For techniques see Table 7 .

\begin{tabular}{|c|c|c|c|c|c|c|}
\hline \multirow[b]{3}{*}{ Expt. no. } & & & \multicolumn{4}{|c|}{ Converted } \\
\hline & \multicolumn{2}{|c|}{ Uninfected clones } & \multicolumn{2}{|c|}{ Pure clones of $Q 1(A 1 b)$} & \multicolumn{2}{|c|}{$\begin{array}{c}\text { Mixed clones of Q1 (A1a } \\
\text { and Q1 (A1B) }\end{array}$} \\
\hline & Total & $\begin{array}{l}\text { Clones of } 10 \\
\text { or more } \\
\text { organisms }\end{array}$ & Total & $\begin{array}{c}\text { Clones of } 10 \\
\text { or more } \\
\text { organisms }\end{array}$ & Total & $\begin{array}{c}\text { Clones of } 10 \\
\text { or more } \\
\text { organisms }\end{array}$ \\
\hline 1 & 16 & 1 & 1 & - & 2 & - \\
\hline 2 & 13 & - & $\mathbf{1}$ & - & - & - \\
\hline $\mathbf{8}$ & 10 & - & 2 & - & 5 & - \\
\hline 4 & 17 & - & 5 & - & $\mathbf{1}$ & 1 \\
\hline $\mathbf{5}$ & 8 & - & $\mathbf{3}$ & - & - & - \\
\hline 6 & 11 & - & $\mathbf{1}$ & - & $\mathbf{5}$ & 1 \\
\hline 7 & $\mathbf{3}$ & - & 1 & - & $\mathbf{2}$ & - \\
\hline 8 & 12 & - & 5 & - & $\mathbf{1}$ & - \\
\hline $\boldsymbol{9}$ & 15 & 2 & - & - & $\mathbf{3}$ & - \\
\hline 10 & 8 & - & 2 & - & 1 & - \\
\hline 11 & 7 & $\mathbf{1}$ & $\mathbf{1}$ & - & 4 & - \\
\hline 12 & $\mathbf{5}$ & - & 4 & - & - & - \\
\hline 18 & 10 & - & 4 & - & 1 & - \\
\hline 14 & 10 & 1 & 4 & - & 2 & - \\
\hline Grand total & 145 & 5 & $\mathbf{8 4}$ & - & 27 & 2 \\
\hline
\end{tabular}

Table 10. Percentages of pure clones and mixed clones of Salmonella typhimurium resulting from infection or superinfection with single particles of phage $A 1 b$

The figures are from Tables 8 and 9 . Bottles or tubes producing ten or more colonies have been excluded on the assumption that they were seeded with more than one bacterium.

S. typhimurium Q1 exposed to phage A1b S. typhimurium Q1 (A1 a) exposed to phage A1b

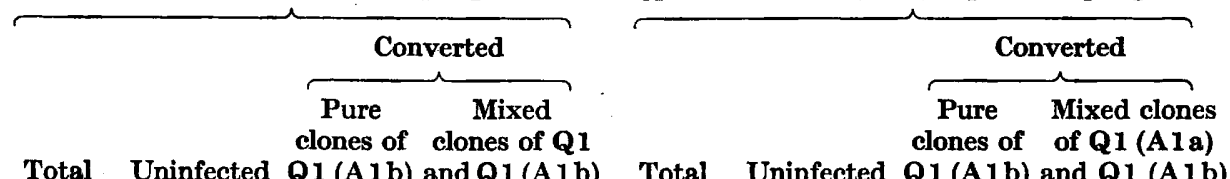

Total Uninfected $Q 1(A 1 b)$ and Q1 (A1b) Total Uninfected Q1 (A1b) and $Q 1$ (A1b)

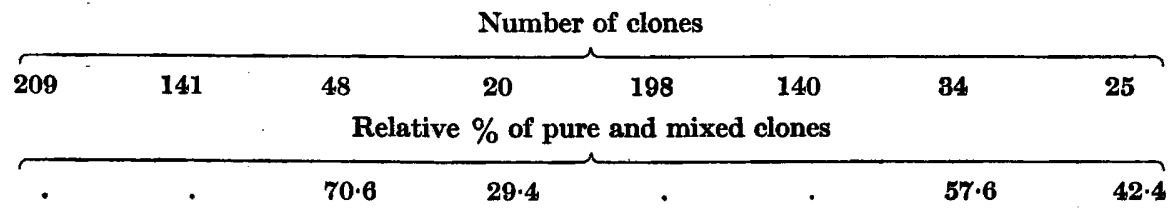


point when exponential growth was well advanced, the number of viable bacteria increased on an average four times in $105 \mathrm{~min}$. The plates or bottles were accordingly incubated from 105 to $120 \mathrm{~min}$. and were expected to give up to a maximum of ten colonies. The presence of more than ten colonies-a rare occurrence-was taken as evidence that the tube or bottle had been charged with more than one bacterium, and this tube or bottle was therefore excluded from further calculations.

In all, thirty such experiments were performed. In fifteen of these, Salmonella typhimurium $Q 1$ was infected with phage $A 1$ b, and in the other fifteen $S$. typhimurium Q1 (A 1 a) was superinfected with this same phage. The results are recorded in Tables 7, 8, 9 and 10. In calculating the average number of bacteria per tube (Table 7) the results of three experiments in which the standard incubation period was exceeded have been excluded. Tables 8 and 9 give the findings in detail, showing the number of tubes or bottles in which only unaffected bacteria were found, the number of tubes or bottles containing only bacteria which had undergone conversion (lysogenization or prophage substitution), and the number of tubes or bottles with mixed clones. These figures, after certain corrections had been made, are consolidated in Table 10. The findings are analysed in the discussion. They show that the majority of the bacteria which were infected by phage produced pure converted clones.

\section{DISCUSSION}

By direct observation it has been shown that, contrary to the experience of other workers who used different conditions of culture (Lark et al. 1955), Salmonella typhimurium Q1, as we have prepared and used it, has a single nucleus. This, before the division of the bacterium as a whole, elongates, becomes indented or dumb-bell shaped, and finally divides. $S$. typhimurium $\mathrm{Q} 1$ is therefore not a binucleate organism in the accepted sense of the term, and is comparable to any other cell which periodically divides into daughter cells, differing from the cells of higher orders only in the short duration of the generation cycle. However, some $25 \%$ of the cells in our standard cultures showed nuclei in varying stages of division, and it is possible that earlier changes, not detectable by microscopic examination, had taken place in an even larger percentage of the organisms. It is to be noted that the percentages of organisms which showed signs of nuclear division (Table 1) were calculated in terms of the total count, which includes viable and non-viable bacteria. We have shown elsewhere (Boyd \& Bidwell, 1961) that about $1 / 3$ of the bacteria in the cultures we use are non-viable. If non-viable organisms are stillborn, or become non-viable at an early stage in their growth cycle, then the percentage of dividing bacteria, calculated in terms of viable bacteria, would be considerably higher than the figures given in Table 1. However, we have no experimental evidence to show the stage at which non-viability supervenes. Bertani (1960) drew attention to the significance of 'doublets' (bacteria which have gone through the internal processes of division, but in which the potential daughters still remain attached to each other, so that for purposes of counting or distribution they remain a single organism) and the somewhat anomalous results which may follow the infection of one-half of such a doublet by a phage particle. Presumably a bacterium may be infected by a phage particle at any stage in its cycle of development, and therefore in $25 \%$ or more the nucleus will have embarked on the process of division when penetration by the phage 
occurs. The bearing which this may have on the occurrence of mixed clones will be discussed later.

The lag-period curves in uncomplicated lysogenization of Salmonella typhimurium Q1 (Fig. 1) shows clearly that the inhibition of bacterial division is largely confined to the first generation, and that subsequently the lysogenized bacteria multiply at approximately the same rate as do the unlysogenized control organisms, though there are exceptions to this rule. Superinfection of $S$. typhimurium Q1 (A 1 a) with phages A1b and A Ic (Fig. 2) follows much the same pattern as simple infection of $S$. typhimurium Q1, with the maximum delay affecting the first generation, but showing a slightly decreased division rate in subsequent generations. The curves given by superinfection with phages $\mathrm{A} 2 \mathrm{~d}$ and $\mathrm{A} 2 \mathrm{e}$, which produce double lysogenization (Boyd \& Bidwell, 1962), are of a peculiar and distinctive pattern. The remarkable decrease in the count of doubly-lysogenized organisms which occurs in the first $15 \mathrm{~min}$. of the experiment is not paralleled by a similar decrease in the number of organisms as counted by the microscope and therefore cannot be the result of bacterial destruction caused by productive development or 'lysis-from-without'. Since adsorption of phage which has been presented in high concentration continues during this period, it is possible that multiple infection of these doublylysogenized organisms may render them non-viable without bringing about immediate lysis. Some similar effect may be responsible for the flat curve following infection of $S$. typhimurium Q1 with phage A2e. Leaving aside these exceptions, the balance of evidence indicates that the major disturbance of bacterial metabolism, as shown by delayed division, occurs in the newly infected or superinfected organism. This is compatible with the conception that the phage establishes its union with the bacterial chromosome before bacterial division occurs, and in doing so upsets the timing of the routine mechanism of division. Conversely, it is unlikely that a cytoplasmic inclusion which persists as such through several generations would disturb the division of the first bacterial division but not of subsequent generations. As can be seen in Table 7, the numbers of uninfected and converted organisms in mixed clones were approximately the same; i.e. there was no runaway multiplication of the uninfected bacteria to suggest that they divided more rapidly than did the converted bacteria.

That productive development is the immediate sequel to the decision to lyse is clearly demonstrated by the results set out in Fig. 3. In so far as the decision to lysogenize is revealed by the establishment of immunity (i.e. protection against the lethal productive development of virulent phage) it can be seen that, given an equal start, this decision precedes and dominates the decision to lyse taken by virulent phage (Tables 3, 4 and 5). Even though immunity stems from the action of only a single lysogenizing particle, it cannot be overborne by a heavy multiple infection with virulent phage (Table 5). Can such immunity be conferred by the lysogenizing particle as a freelance cytoplasmic inclusion, or does it indicate that the phage has linked up with the bacterial chromosome as prophage and, in its role of supplementary gene, is playing its part in regulating the metabolism of the organism by causing a specific repressor to be elaborated?

It was to confirm or refute the suggestion that the phage DNA remains for one or more generations as a cytoplasmic inclusion or pre-prophage that the experiments recorded in Tables 7, 8, 9 and 10 were performed. The total number of viable bacteria 
cultured from each tube in the various experiments provides information of some significance (Table 6). Where converted clones developed, the average number of bacteria was significantly lower than in the clones of non-infected bacteria. This is of course, a result of the lag period. The total number of bacteria in the mixed clones was slightly higher than in the non-infected clones, but the number of converted bacteria was practically the same in both the mixed and converted series, namely 3 , $2 \cdot 85,2 \cdot 9$ and $2 \cdot 8$, respectively. This strongly suggests that in both series the process of division had been in progress for the same length of time or, in other words, that in pure converted clones and in mixed clones the parent lysogenic bacteria took origin about the same time, and that in the mixed clones lysogenesis was"not delayed until the pre-prophage had passed through one or more generations as an unattached cytoplasmic inclusion. Further evidence to this effect is to be found in the relative proportions of uninfected and converted organisms in the mixed clones. If the pre-prophage does in fact remain unattached for one or more bacterial generations, then the first bacterial division will produce an uninfected organism and one containing pre-prophage. If during this generation the pre-prophage becomes prophage, then after the next bacterial division the clone will contain two uninfected and two converted bacteria, and in subsequent divisions the numbers of the two types will remain approximately equal. If, however, the pre-prophage is again carried over unattached, the score would be three uninfected and one infected bacteria. Thus it is to be expected that the uninfected bacteria would always outnumber the infected or converted ones. However, this does not happen. Results, not recorded in the tables, show that in the phage A1 b versus Salmonella typhimurium Q1 experiments, 13 of the 20 mixed clones gave a distribution of this pattern, but in the remaining 7 clones the position was reversed, as one or two uninfected organisms occurred in association with from three to seven converted ones. In the superinfection experiments 9 of 24 mixed clones showed similar reversed proportions of non-infected and converted organisms.

The consolidated figures in Table 9 show that when Salmonella typhimurium Q1 was exposed to a low multiplicity of infection with phage $A 1 \mathbf{b}$ (a single infection in the majority) some $\mathbf{7 0} \%$ of the infected bacteria were converted before division occurred, and so produced pure clones: the remaining $30 \%$ gave mixed clones. Corresponding figures for the superinfection of $S$. typhimurium Q1 (A 1 a) with phage $A 1 \mathrm{~b}$ are roughly 59 and $41 \%$. Clearly lysogenization-the integration of the phage genetic material as prophage into the chromosome of the bacterium-occurred before the first division in the majority of cases. What then is the explanation of the mixed clones? With the distribution technique which was used and the corrections which were made, it cannot be attributed to the introduction of two separate bacteria into one tube. On the other hand, it may be related to infection of a bacterium in which the nucleus has already embarked on the process of division. The conception of unilateral infection of a doublet-a cell in which nuclear division is complete although separation of the daughters has not yet taken place-presents no difficulty. But, if infection occurs during the early stages of nuclear division, what happens? It seems improbable that an undivided 'pre-prophage' could attach itself to a partially-divided nucleus and accelerate its own rate of division so as to come into step with the dividing chromosome and thus produce ultimately two prophagebearing daughter chromosomes. The alternative would be to remain unattached until 
division of the chromosome had reached the stage when two separate sites of attachment, one on each of the daughter chromosomes, were available, and then to become attached as prophage to one of these sites. This would result in a unilaterally lysogenic doublet. Followed to its logical conclusion, this theory implies that every organism in which nuclear division has started when it becomes infected with a single particle of temperate phage is destined to become a unilaterally infected doublet and the potential parent of a mixed clone. In terms of this theory the conception that, after penetration of the bacterium, the phage DNA becomes preprophage and remains for some time a free cytoplasmic inclusion would be correct in a limited sense. In an organism in which nuclear division had started, the preprophage would remain 'free' until such division was completed. There is no reason, however, to think that it would remain unattached for one or more bacterial generations.

In summary, it may be said that the results of the present culture experiments, together with various items of indirect evidence (lag period, early establishment of immunity, analogy of decision to lyse and immediate onset of productive development), suggest that in single infections and superinfections with stable temperate phage, in this particular Salmonella typhimurium system, lysogenization is completed before the infected bacterium divides. When the phage penetrates the bacterium before the start of nuclear division the result in culture is to produce a pure clone of lysogenic bacteria. When infection occurs after nuclear division has started, the phage DNA remains as pre-prophage until the nucleus divides, and then becomes attached as prophage to one of the halves, forming a unilaterally lysogenic doublet. If such a unilaterally lysogenic doublet is separated and cultured individually before it divides, it gives rise to a mixed clone of uninfected and converted progeny. This theory is compatible with the numbers of bacteria with dividing nuclei present in our cultures, remembering that the percentages given in Table 3 relate to the total count, and might be considerably higher if it were possible to calculate them in terms of viable bacteria.

How are these conclusions to be reconciled with the currently accepted theory that pre-prophage remains as an unattached cytoplasmic inclusion for one or more generations? This was first suggested by Lieb (1953), who infected Escherichia coli $\mathrm{K} 12$ with phage $\lambda$ at a multiplicity of 3 to 20 , and found mixed clones arising from the progeny of single bacteria treated in this way. She calculated that the period intervening between penetration of the bacterium by the phage and the establishment of lysogenesis was about one hour. Bertani (1954) found a similar state of affairs in superinfections of lysogenic strains of Shigella dysenteriae with multiple infections of phage P2 (originally derived from Escherichia coli) and certain of its mutants. He proposed the name 'pre-prophage' for the unattached phage genetic material and suggested that in the pre-prophage state some multiplication of the phage components may occur. This theory gains weight from an observation made by Levine (1957), who found that in mixed infections of Salmonella typhimurium with mutants of phage $\mathbf{P 2}$ a good proportion of the lysogenized bacteria carried prophages with markers from both phages, which suggested that multiplication and genetic recombination had occurred. Luria (1959) recorded experiments in which $\boldsymbol{S}$. typhimurium was exposed to phage P22, resulting in extensive segregation of sensitive non-carrier bacteria in practically every clone. In some cases carrier 
bacteria continued to harbour more than one type of phage for many generations. He regarded the early establishment of a prophage in one cell nucleus as an unlikely event. Further experiments were done in which single clones of S. typhimurium infected with phage P22 were analysed by using micromanipulation by a modified De Fonbrunne technique. Each of these clones was the progeny of a single bacterium that had been infected with phage particles of one or more genetic types. It was found that, even with multiple infections, a phage element could be maintained for several generations by single unilinear transmission within a clone that continued to produce non-carrier sensitive bacteria. Such clones occasionally gave a typical lysogenic subclone. Clearly these results, and particularly those reported by Luria (1959), are completely at variance with ours.

Why should this be? Two possible explanations may be suggested. (1) Our experiments were made with single infections, the other experiments with multiple infections. In the case of Lieb's original observation, this appears to be the only difference. (2) The phages used were not stable wild strains, but were mutants. In some of the experiments lysogenic bacteria were superinfected with a related phage mutant, in others non-lysogenic sensitive bacteria were exposed simultaneously to two different phage mutants. Without a detailed study of the overall characters of these mutants, particularly of their stability and lysogenizing properties when used singly, no reliable conclusion can be reached. Nevertheless, it seems possible that related and perhaps unstable mutants when present as multiple infections and when competing with each other for a particular site on the chromosome, might for a time mutually obstruct lysogenization. This is a theory which could be confirmed or disproved by suitable experiment. A third possibility to be considered in relation to the micromanipulator experiments (Luria, 1959) is that the parent bacterium of the clone, picked out in this way, may have been a unilaterally infected doublet. If similar results were obtained consistently and repeatedly, as no doubt they were, this explanation can be disregarded.

\section{REFERENCES}

Bertant, G. (1953). Lysogenic versus lytic cycle of phage multiplication. Cold Spr. Harb. Symp. quant. Biol. 18, 65.

Bertani, G. (1954). Studies in lysogenesis. III. Superinfection of lysogenic Shigella dysenteriae with temperate mutants of the carrier phage. J. Bact. 67, 696.

Bertani, G. (1958). Lysogeny. Advanc. Virus Research, 5. New York: Academic Press Inc.

Bertani, G. (1960). On the interpretation of Boyd's 'multiplicity effect' in lysogenisation. Virology, 12, 132.

Boyd, J. S. K. (1950). The symbiotic bacteriophages of Salmonella typhimurium. J. Path. Bact. 62, 501.

Boyd, J. S. K. (1951). Mutation in a bacterial virus. Nature, Lond. 168, 994.

Boyd, J. S. K. \& BIDwell, D. E. (1957). The type A phages of Salmonella typhimurium; identification by a standardised cross-immunity test. J. gen. Microbiol. 16, 217.

Boyd, J. S. K. \& BIDwell, D. E. (1959). The Q1 (A) strains of Salmonella typhimurium; induction phenomena. J. gen. Microbiol. 21, 635.

Boyd, J. S. K. \& BIDwell, D. E. (1961). The type A phages of Salmonella typhimurium; observations on temperate phage and lysogenesis. J. gen. Microbiol. 26, 443.

Boyd, J. S. K. \& BIDwELL, D. E. (1962). Superinfection of lysogenic strains of Salmonella typhimurium Q1: prophage substitution and double lysogenization. J. gen. Microbiol. 29, 659 . 
$\mathrm{J}_{\mathrm{ACOB}}$, F. \& Wollman, E. (1953). Induction of phage development in lysogenic bacteria. Cold Spr. Harb. Symp. quant. Biol. 18, 101.

LARK, K. G. \& MAAløe, O. (1954). The induction of cellular and nuclear division in Salmonella typhimurium by means of temperature shifts. Biochim. biophys. Acta, 15, 345.

LaRK, K. G., MaAløe, O. \& Rostock, O. (1955). Cytological studies of nuclear division in Salmonella typhimurium. J. gen. Microbiol. 13, 318.

Levine, M. (1957). Mutations in temperate phage P22 and lysogeny in Salmonella. Virology, 3, 22.

LIEB, M. (1953). The establishment of lysogenicity in Escherichia coli. J. Bact. 65, 642.

LURIA, S. E. (1959). Lysogeny and lysogenisation-studies in infectious heredity. A Symposium on Molecular Biology. University of Chicago Press.

Lwoff, A., Kaplan, A. S. \& Ritz, E. (1954). Recherches sur la lysogénisation de Salmonella typhimurium. Ann. Inst. Pasteur, 86, 127. 